\title{
MENUMBUHKAN KESADARAN LINGKUNGAN KEPADA GURU-GURU SD DI SEKITAR SUNGAI CITARUM MELALUI PENYULUHAN TENTANG HAKEKAT SAINS DALAM PEMBELAJARAN
}

(Program Pengabdian Di Wilayah Cikaobandung Kecamatan Jatiluhur Kabupaten Purwakarta)

\author{
Siti Ruqoyyah¹, Linda Hania Fasha², Euis Eti Rohaeti ${ }^{3}$ \\ 1,2,3 IKIP Siliwangi \\ siti-ruqoyyah@ikipsiliwangi.ac.id¹ 1 , lindahania@ikipsiliwangi.ac.id² ${ }^{2}$ 2rht@yahoo.com
}

\begin{abstract}
ABSTRAK
Secara umum, tujuan jangka panjang program pengabdian ini adalah mengembangkan suatu proses pengabdian melalui penyuluhan bagi guru-guru SD dalam upaya menumbuhkan kesadaran lingkungan kepada guru-guru SD di sekitar Sungai Citarum tentang hakekat sains dalam pembelajaran. Adapun target khusus yang ingin dicapai adalah meningkatkan pemahaman dan kesadaran lingkungan serta pemahaman strategi dan pendekatan pembelajaran yang mungkin dilakukan guru-guru SD mengenai pentingnya pelestarian lingkungan melalui konteks lingkungan di sekitar Sungai Citarum yang dikaitkan dengan hakekat sains untuk pembelajaran SD. Metode pelaksanaan pada kegiatan pengabdian ini dikelompokan menjadi empat tahap kegiatan yaitu tahap persiapan terdiri dari kegiatan observasi, pelaksanaan terdiri dari kegiatan penyuluhan, evaluasi terdiri dari kegiatan mengevaluasi kegiatan, dan penyelesaian terdiri dari kegiatan penyusunan laporan dan publikasi luaran kegiatan pengabdian kepada masyarakat. Hasil dari kegiatan pengabdian masyarakat ini yaitu guru-guru memahami mengenai pentingnya pelestarian lingkungan melalui konteks lingkungan di sekitar Sungai Citarum yang dikaitkan dengan hakekat sains, terwujudnya kesadaran guru-guru SD akan pentingnya pelestarian lingkungan serta guru-guru SD memahami strategi dan pendekatan pembelajaran yang mungkin dilakukan, yang menjadi dasar untuk menumbuhkan kesadaran mengenai pentingnya pelestarian lingkungan dikaitkan dengan pembelajaran di SD.
\end{abstract}

Kata Kunci : kesadaran lingkungan, hakekat sains dalam pembelajaran.

\begin{abstract}
In general, the long-term goal of this service program is to develop a service process through counseling for elementary school teachers to raise environmental awareness among elementary school teachers around the Citarum River about the nature of science in learning. The specific target to be achieved is to increase the understanding and awareness of the environment as well as the understanding of strategies and learning approaches that might be done by elementary school teachers about the importance of environmental preservation through the environmental context around the Citarum River which is associated with the nature of science for elementary school learning. The implementation methods in this service activity are grouped into four activity stages, namely the preparation phase consisting of observation activities, the implementation consists of counseling activities, the evaluation consists of evaluating activities, and the completion consists of reporting activities and publication of outputs of community service activities. The results of these community service activities are that the community understands the importance of environmental preservation through the environmental context around the Citarum River which is associated with the nature of science, the realization of elementary school teachers' awareness of the importance of environmental preservation and elementary school teachers understand the strategies and learning approaches that might be carried out, which is the basis for raising awareness about the importance of environmental conservation associated with learning in elementary schools.
\end{abstract}

Keywords: environmental awareness, counseling, the nature of science in learning. 


\section{A. PENDAHULUAN}

Wilayah Cikaobandung Kecamatan Jatiluhur Kabupaten Purwakarta merupakan salah satu desa yang teraliri Sungai Citarum. Beberapa tahun kebelakang, desa ini sering sekali menjadi langganan banjir apalagi jika musim penghujan datang. Hal ini diakibatkan karena kiriman air dari hulu dan anak sungai sebgai pemacu. Selain itu, tingginya curah hujan menjadi pemicu utama naiknya debit Citarum. Namun, faktor rusaknya daerah tangkapan air, akibat alih fungsi lahan dan penebangan pohon, di sepanjang daerah aliran sungai juga tidak bisa diabaikan (Kompas, 2010). Banyak warga yang terpaksa mengungsi karena rumahnya terendam oleh luapan Sungai Citarum. Namun, kejadian ini sudah tidak terjadi karena sudah ada penanganan dari pemerintah yaitu pembangunan tanggul dan normalisasi bantaran Sungai Citarum di wilayah itu.

Agar kejadian serupa tidak terulang kembali, perlu adanya upaya atau cara dalam menghindari hal tersebut. Diantaranya adalah adanya kesadaran akan pentingnya pelestarian lingkungan dari setiap elemen masyarakat khususnya guru dan siswa. Guru dan siswa merupakan tonggak dalam sebuah perubahan. Pemahaman guru dan siswa akan pentingnya pelestarian lingkungan yang mereka pelajari pada pembelajaran sains merupakan hal yang mendasar dalam menjaga dan merawat lingkungan.

Pembelajaran sains di sekolah dasar memiliki peran strategis dalam menumbuhkan kesadaran tentang alam serta pemberdayaan dan pelestariannya. Kesadaran tentang alam ini, sangat penting bagi seluruh generasi muda karena merekalah yang memikul tanggung jawab terhadap pelestarian alam tersebut di masa yang akan datang (Tytler, 2010; Lamanauskas, 2009). Alam merupakan ciptaan Tuhan yang memiliki keterbatasan, sehingga isu pelestarian serta pemberdayaannya secara positif harus menjadi sikap kultural dari seluruh anggota masyarakat. Tanpa kesadaran kolektif, maka nasib generasi mendatang tentu akan berada pada kesulitan yang mendasar paling tidak berkenaan dengan tiga jenis krisis yaitu krisis energi, krisis pangan dan papan, serta krisis lingkungan hidup. Masalah ini merupakan tanggung jawab kolektif seluruh masyarakat termasuk dunia pendidikan. Dengan demikian, menumbuhkan kesadaran tentang krisis lingkungan hidup ini harus ditanamkan sejak dini antara melalui proses pendidikan termasuk di sekolah dasar.

Walaupun pendidikan sains dipandang penting dan strategis bagi kehidupan manusia, namun dalam pelaksanaannya masih banyak menghadapi permasalahan. Hal 
ini ditunjukkan dalam hasil studi PISA (the Programme for International Student Assessment) yang mengungkapkan rendahnya ketertarikan siswa dalam belajar sains di berbagai Negara (Thomson \& De Bortoli, 2008). Sementara tradisi pembelajaran sains yang banyak dikembangkan di sekolah, termasuk di sekolah dasar, cenderung lebih berorientasi pada transfer pengetahuan serta konteksnya kurang relevan dengan kehidupan sehari-hari (Aikenhead, 2006). Study Aikenhead juga menemukan bahwa upaya pengembangan pembelajaran sains yang lebih memperhatikan prinsip-prinsip hakekat sains, masih belum menjadi perhatian serius di lapangan. Fakta ini juga tergambar dari hasil studi pendahuluan yang dilakukan di salah satu Sekolah Dasar di Kota Bandung. Data yang dianalisis dalam penelitian pendahuluan ini bersumber dari rekaman pembelajaran sain di kelas 5 sekolah dasar dengan topik listrik.

Permasalahan lingkungan hidup merupakan hal yang serius, baik bagi individu maupun kelompok masyarakat. Manusia dengan lingkungannya senantiasa terjadi interaksi, yaitu memengaruhi dan sekaligus dipengaruhi oleh lingkungan hidupnya, atau membentuk dan dibentuk oleh lingkungan hidupnya (Nurdin, 2014). Diperlukan kearifan mengenai permasalahan tersebut agar tidak terjadi kembali. Perlu adanya program yang dapat menumbuhkembangkan kesadaran dan pengetahuan khusus guruguru SD mengenai strategi dan pendekatan pembelajaran mengenai pentingnya pelestarian lingkungan melalui konteks lingkungan di sekitar Sungai Citarum. Inilah yang membuat peneliti tertarik untuk diadakannya penyuluhan kepada guru-guru SD di sekitar Sungai Citarum tentang hakekat sains dalam pembelajaran. Adapun tujuan yang ingin dicapai adalah meningkatkan pemahaman dan kesadaran lingkungan serta pemahaman strategi dan pendekatan pembelajaran yang mungkin dilakukan guru-guru SD mengenai pentingnya pelestarian lingkungan melalui konteks lingkungan di sekitar Sungai Citarum yang dikaitkan dengan hakekat sains untuk pembelajaran SD.

\section{B. LANDASAN TEORI}

\section{Kesadaran Lingkungan}

Kesadaran adalah keadaan sadar, bukan merupakan keadaan yang pasif melainkan suatu proses aktif. Menurut Atkinson et.al (Afandi, Neolaka \& Saleh,2012), "Kesadaran adalah tingkat kesiagaan individu pada saat ini terhadap rangsangan eksternal dan internal, artinya terhadap peristiwa-peristiwa lingkungan dan suasana tubuh, memori 
dan pikiran". Kesadaran adalah sadar dengan apa yang dilakukan dan dapat menentukan baik atau buruk dari apa yang dilakukan.

Menurut Joedianto (2017) "Lingkungan berasal dari kata lingkung yang berarti sekeliling, sekitar. Lingkungan adalah bulatan yang melingkungi atau melingkari, sekalian yang terlingkung disuatu daerah sekitarnya". Lingkungan adalah alam sekitar termasuk orang-orangnya di dalamnya yang mempengaruhi manusia sebagai anggota masyarakat dalam kehidupan dan kebudayaannya.

Dari pernyataan di atas dapat disimpulkan, kesadaran lingkungan adalah upaya menumbuhkan kesadaran seseorang untuk dapat peduli terhadap lingkungan atau tempat disekitar orang tersebut tinggal. Kesadaran lingkungan bagi guru dan peserta didik berguna untuk meneliti (examine) isu lingkungan yang utama dari sudut pandang lokal, nasional, region dan internasional. Menurut Mutiani (2017), Tekanan mengenai kompleksitas masalah lingkungan, diharapkan mampu memunculkan kemampuan untuk berfikir kritis dengan keterampilan untuk memecahkan masalah. Fokus nilai yang terkandung dari sikap kesadaran lingkungan ialah pentingnya kerjasama lokal, nasional dan internasional untuk mencegah dan memecahkan masalah-masalah lingkungan, secara eksplisit dapat mempertimbangkan/memperhitungkan aspek lingkungan dalam rencana pembangunan dan pertumbuhan berkelanjutan.

\section{Hakekat Sains dalam Pembelajaran}

Hakekat sains menurut Harlen dan Qualter (2004) meliputi delapan aspek berikut: (1) Investigasi sain menggunakan metode bervariasi, (2) Pengetahuan sain berdasar atas bukti empiris, (3) Pengetahuan sain terbuka untuk direvisi, (4) Model, hukum, mekanisme, dan teori sain menjelaskan fenomena sain, (5) Sain adalah sebuah cara untuk memahami, (6) Pengetahuan sain mengasumsikan sistem yang teratur dan konsisten, (7) Sain merupakan upaya manusia, (8) Sain selalu mengajukan pertanyaan tentang alam dan dunia. Delapan aspek hakikat sains tersebut sangatlah penting menjadi acuan dalam pembelajaran sains, termasuk di sekolah dasar, dengan beberapa alasan. Pertama, perkembangan pengetahuan sains bagi anak perlu dilakukan melalui proses yang baik sehingga pengalaman belajar mampu memberikan makna mendalam tentang fenomena alam dan menumbuhkan kesadaran serta sikap bijaksana dalam menghadapinya. Kedua, pengalaman belajar melalui proses sain yang baik sebagaimana diharapkan dalam hakikat sains, dapat menumbuhkan kemampuan berpikir saintifik yang sangat berguna baik untuk kehidupan maupun pengalaman belajar selanjutnya. 
Ketiga, Pengalaman belajar sains yang mempertimbangkan prinsip-prinsip hakikat sains berpotensi memberikan dampak kesadaran pada peserta didik tentang kedudukan dan peran manusia dalam memberdayakan potensi alam serta upaya melestarikannya.

Salah satu aspek yang dimuat hakikat sain adalah sain merupakan upaya manusia, termasuk pembelajarannya. Berbagai cara untuk memperkenalkannya melalui pendidikan telah banyak dikaji (Lederman, 2007). Menurut studi Lederman, banyak upaya yang telah dilakukankan untuk mengembangkan aspek-aspek hakikat sain (NOS), akan tetapi NOS pada awalnya hanya dipandang sebagai bagian sain yang bersifat implisit. Berdsarkan hasil analisisnya terhadap berbagai studi terdahulu, Lederman (2007) menyimpulkan bahwa pembelajaran NOS secara implisit sama sekali tidaklah efektif hasilnya.

\section{METODE PELAKSANAAN}

Pelaksanaan program pengabdian kepada masyarakat ini dilaksanakan selama 1 minggu di bulan agustus mulai dari tanggal 5-10 Agustus 2019 di Kabupaten Purwakarta. Metode pelaksanaan pada kegiatan pengabdian ini dikelompokan menjadi empat tahap kegiatan yaitu:

1. Tahap persiapan

Tahap persiapan dilakukan dengan survei awal melalui pedoman observasi dan studi dokumentasi untuk melihat gambaran masyarakat dan permasalahan di masyarakat khususnya guru-guru di sekitaran Sungai Citarum. Kegiatan selanjutnya adalah sosialisasi terhadap kegiatan yang akan dilakukan serta melakukan perijinan tempat penyuluhan. Selanjutnya, penyusunan rancangan pengabdian meliputi penyiapan bahan, strategi pelaksanaan, serta penetapan job description.

\section{Tahap Pelaksanaan}

Pada tahap pelaksanaan ini dilakukan kegiatan penyuluhan. Kegiatan penyuluhan dilakukan melalui model lokakarya atau workshop. Pelaksanaan pengabdian meliputi workshop dan aktivitas lapangan yang melibatkan guru-guru sekolah dasar di sekitar sungai Citarum.

\section{Tahap Evaluasi}

Pada tahap ini terdiri dari kegiatan mengevaluasi kegiatan berupa evaluasi hasil pelaksanaan, pelaporan. 
4. Tahap Penyusunan Laporan dan Publikasi Luaran

Penyusunan laporan dan publikasi luaran kegiatan pengabdian kepada masyarakat mengikuti rancangan jadwal yang sudah direncanakan.

\section{HASIL DAN PEMBAHASAN}

\section{Hasil}

Pengabdian pada masyarakat yang dilaksanakan di daerah Citarum kepada guruguru Sekolah Dasar dengan menggunakan model lokakarya atau workshop yang meliputi identifikasi konteks lingkungan di sekitar sungai citarum yang relevan, pengkajian konteks tersebut dalam kaitannya dengan bagian dari hakekat sains yang relevan, serta pembahasan strategi dan pendekatan pembelajaran yang bisa dilakukan sehubungan dengan konteks terpilih serta hakikat sains yang menjadi dasarnya. Pengabdian pada masyarakat ini bertema workshop yang berjudul "Menumbuhkan Kesadaran Lingkungan Kepada guru-guru SD Di sekitar Sungai Citarum Melalui Penyuluhan Hakekat Sains dalam Pembelajaran “. Program pengabdian ini dilaksanakan selama 1 minggu dari tanggal 5-10 agustus 2019 dengan peserta sebanyak 125 peserta.

Langkah pertama program pengabdian ini adalah survei awal, sosialisasi dan perijinan. Sosialisasi dan perijinan merupakan tahap awal kegiatan. Kegiatan ini bertujuan untuk menginformasikan kepada guru-guru SD mengenai sasaran dan rencana kegiatan pengabdian. Koordinasi masalah waktu dan tempat pelaksanaan dengan pihak terkait yang menjadi target pengabdian masyarakat, yaitu dinas terkait dan sekolah yang menjadi sasaran. Kegiatan ini dilakukan dengan metode diskusi langsung dengan pejabat yang berwenang di bidang pendidikan di wilayah yang menjadi lokasi pengabdian.

Langkah selanjutnya penyusunan rancangan pengabdian meliputi penyiapan bahan, strategi pelaksanaan, serta penetapan job description. Pelaksanaan pengabdian meliputi workshop dan aktivitas lapangan yang melibatkan guru-guru sekolah dasar di sekitar sungai Citarum. Guru-guru sekolah dasar diberikan workshop tentang pentingnya hakikat sains dalam menumbuhkan kesadaran lingkungan serta beberapa penyuluhan dalam mengelola lingkungan sekolah menjadi lebih bersih dan dapat memanfaatkan bahan-bahan daur ulang di sekitar sekolah dengan menggunakan indikator dari hakikat sains yang dapat langsung di aplikasikan. 


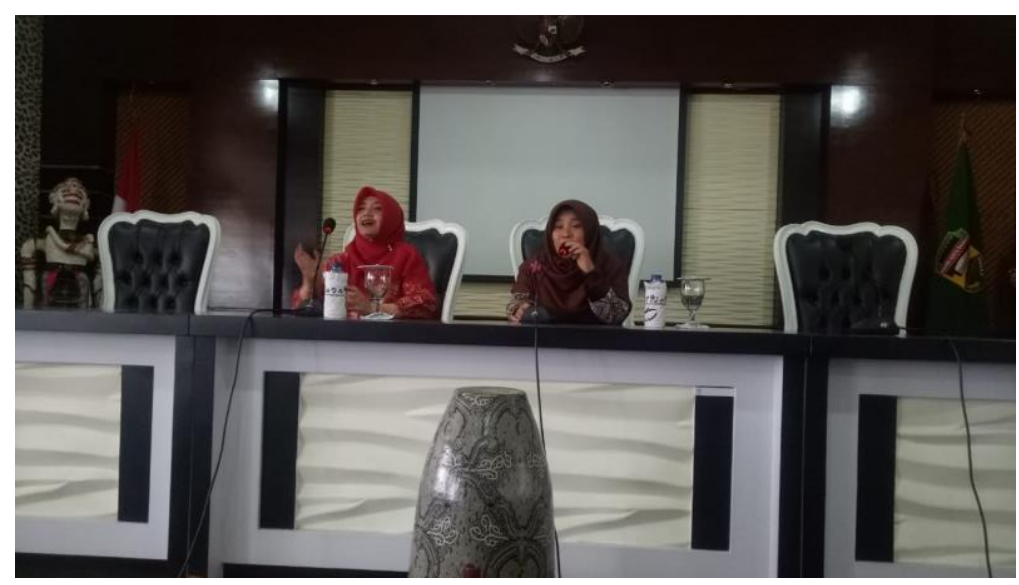

Gambar 1. Kegiatan Penyuluhan

Kegiatan selanjutnya adalah evaluasi. Kegiatan evaluasi ini berupa hasil pelaksanaan, pelaporan, dan penulisan artikel yang dilakukan dalam kegiatan ini dilaksanakan dengan tidak terlalu formal namun tetap dilaksanakan evaluasi terkait pemahaman guru-guru dalam menyusun bahan ajar sesuai dengan strategi atau pendekatan yang berkaitan dengan hakekat sains dalam pembelajaran. Evaluasi menggunakan format wawancara dan dokumentasi.

\section{Pembahasan}

Pada kegiatan program pengabdian ini guru-guru merasa antusias dan aktif. Guru-guru peserta pengabdian mendapatkan pembelajaran hakekat sains dan penerapannya dalam menggunakam strategi atau pendekatan yang berkaitan dengan hakekat sains mengenai pelestarian lingkungan di sekitar wilayah sungai Citarum. Guru-guru peserta pengabdian mengetahui bagaimana tentang pentingnya hakikat sains dalam menumbuhkan kesadaran lingkungan serta beberapa penyuluhan dalam mengelola lingkungan sekolah menjadi lebih bersih dan dapat memanfaatkan bahan-bahan daur ulang di sekitar sekolah dengan menggunakan indikator dari hakikat sains yang dapat langsung di aplikasikan.

Temuan yang didapatkan di lapangan bahwa guru-guru pada umumnya belum memahami makna dari hakekat sains itu sendiri. Guru-guru belum mengetahui teori mengenai sains tetapi belum dapat di aplikasikan pada pembelajaran di sekolah. Selain temuan kedua yang didapatkan, banyak guru yang belum dapat memanfaatkan barangbarang bekas daur ulang yang ada dilingkungan sekolah tempat mereka mengajar. Temuan lainnya, pengabdian pada masyarakat ini memerlukan perencanaan yang matang dan pendekatan kepada subjek pengabdian yaitu guru-guru agar lebih siap ketika penyuluhan di selenggarakan. 
Hambatan yang terjadi dalam pelaksanaan dalam program pengabdian ini diantara nya adalah lokasi pengabdian di pinggiran kota kemudian akses sarana dan prasarana juga menjadi salah satu hambatan yang terjadi terjadi di lapangan.

\section{E. KESIMPULAN}

Berdasarkan hasil pelaksanaan pengabdian pada masyarakatyang telah dilaksanakan di Wilayah Cikaobandung Kecamatan Jatiluhur Kabupaten Purwakarta, maka dapat disimpulkan hal-hal sebagai berikut:

1. Kegiatan pengabdian pada masyarakat ini dapat memberikan manfaat langsung kepada guru-guru SD khususnya di Wilayah Cikaobandung Kecamatan Jatiluhur Kabupaten Purwakarta dalam meningkatkan pemahaman tentang hakekat sains dalam pembelajaranmengenai pentingnya pelestarian lingkungan di sekitar Sungai Citarum.

2. Kegiatan pengabdian pada masyarakat ini dapat dijadikan dapat memberikan pemahaman strategi dan pendekatan pembelajaran yang mungkin dilakukan, yang menjadi dasar untuk menumbuhkan kesadaran mengenai pentingnya pelestarian lingkungan dikaitkan dengan pembelajaran di SD.

\section{F. DAFTAR PUSTAKA}

Afandi, A., Neolaka, A., \& Saleh, R. (2012). Kesadaran lingkungan masyarakat dalam Pemeliharaan taman lingkungan di Jakarta Pusat. Jurnal Menara Jurusan Teknik Sipil FT.UNJ, 7(1), 54-66.

Aikenhead, G. (2006). Science education for everyday life. New York: Teachers' College Press.

Harlen, W., \& Qualter, A. (2004). The teaching of science for primary scools (forth edition). London: David Fulton Publishers.

Joedianto, Y. D. B. (2017). Pengaruh kesadaran masyarakat atas lingkungan hidup terhadap minat masyarakat menabung di bank sampah " sawo kecik "Perumahan Candi Gebang Permai Yogyakarta. [Online]. Diakses dari: https://repository.usd.ac.id/22229/2/132214160 full.pdf.

Kompas. (2010). Titik tertinggi air Jatiluhur. [Online]. Diakses dari: https://regional.kompas.com/read/2010/03/23/04072745/titik.tertinggi.air.jatilu hur.

Lamanauskas, V. (2009). The process of natural science education in primary school: the importance of chemistry component. In M. Bilek (Ed.). Research, Theory and Practice 
in Chemistry Didactics, XIX, $1^{\text {st }}$ Part: Research Articles and Theoretical Studies (pp. 1320). Hradec Kralove: Gaudeamus.

Lederman, N.G., Lederman, J.S. \& Antink, A. (2013). Nature of science and scientific inquiry as contexts for the learning of science and achievement of scientific literacy. International Journal of Education in Mathematics, Science and Technology, 1(3), 138-147).

Mutiani. (2017). IPS dan pendidikan lingkungan: urgensi pengembangan sikap kesadaran lingkungan peserta didik. Sosio Didaktika. 4(1), 45-53.

Nurdin. 2014. Pengaruh metode penyuluhan dan tingkat pendidikan terhadap pengetahuan berwawasan lingkungan. Jurnal Ilmu Pendidikan. 20(2), 201-206.

Thomson, S., \& De Bortoli, L. (2008). Exploring scientific literacy: how Australia measures up. Camberwell, Victoria: Australian Council for ducational Research Ltd.

Tytler, R. (2010). Ways forward for primary science education: a review commissioned by the Swedish National Agency for Education. Melbourne: Deakin University. 